\title{
Can interest rate spreads stabilize the euro area? *
}

\author{
Michał Brzoza-Brzezina $^{\dagger} \quad$ Jacek Kotłowski $^{\ddagger} \quad$ Kamil Wierus $^{\S}$
}

Preliminary draft

\begin{abstract}
Over the last few years significant spreads arose for both public and private debt between euro area countries. We check whether these spreads could be made to work towards the goal of providing more stability to the euro area. In particular we focus on reducing the imbalances that arose between the core and peripheral members of the euro area in the first decade of its existence. The idea is that stable, positive spreads in peripheral countries could have decreased domestic demand thus preventing the boombust cycles that plagued these economies. They could also prevent such developments in the future. We find that real interest rates higher by 1.5 to 5.8 percentage points would have been necessary to stabilize the four peripheral euro area member countries.
\end{abstract}

$J E L: \mathrm{E} 32, \mathrm{E} 43, \mathrm{E} 52$,

Keywords: Euro area, imbalaces, current account, panel estimation

${ }^{*}$ The views expressed herein are those of the authors and not necessarily those of the National Bank of Poland or the Warsaw School of Economics.

${ }^{\dagger}$ National Bank of Poland and Warsaw School of Economics; Email: michal.brzoza-brzezina@nbp.pl.

${ }_{\ddagger}^{\ddagger}$ National Bank of Poland and Warsaw School of Economics; Email: jacek.kotlowski@nbp.pl.

$\S$ National Bank of Poland; Email: kamil.wierus@nbp.pl. 


\section{Introduction}

Over the first decade of its existence the euro area whitnessed deep imbalances between its core and peripheral members. One of the most important reasons behind their build-up were (approximately) equal nominal interest rates across the common currency area. According to several studies these rates were too low for some members and too high for others both in nominal and real terms (Honohan and Leddin (2006); Blanchard (2007); Brzoza-Brzezina et al. (2014)). The latter aggravated the problem since inflation rates in peripheral countries tended to be relatively high bringing real rates to even lower levels (ECB, 2003; Zdarek and Aldasoro, 2009). As a result several peripheral economies of the euro area faced boom-bust cycles $^{1}$. Rapid growth of internal demand, driven by mild financing conditions, boosted somewhat domestic output, but the bulk of additional demand was supplied from abroad. At the same time domestic inflation picked up and started to exceed that of core euro area countries. As a result of high demand and lost competitiveness current account deficits increased strongly.

Things changed when the financial crisis broke out. Interest rates started to diverge. Risk premia in highly indebted countries contributed to higher spreads on sovereign debt and bank loans to the private sector. Domestic demand in peripheral economies collapsed and current account deficits narrowed sharply (for instance the unweighted average CA/GDP ratio for Greece, Portugal and Spain increased from -11.6\% in 2007 to -1.8\% in 2012). Their external positions improved amid a deep recession, whose seeds were sawn during the preceeding boom.

These developments bring forward the idea that interest rate spreads between euro area countries could be exploited in a way that brings more stability to the euro area. However, it should be made clear from the very beginning that we do not speak of variable spreads as they emerged recently. These proved to work in exactly the oposite way they should. They increased in depressed, peripheral countries making recovery even more difficult. This was recently deemed worrying by the ECB President. Mario Draghi rightly pointed out that this could impair the proper working of monetary transmission in the euro area (Draghi, 2012).

\footnotetext{
${ }^{1}$ As a matter of fact the problem affected also (and sometimes even more) countries that addopted hard pegs against the euro, Estonia, Latvia and Lithuania (Kuodis and Ramanauskas, 2009; Brixiova et al., 2009).
} 
In contrast, we speak of stable spreads that could bring more stability to the euro area. If peripheral countries faced higher, average interest rates in the past, imbalances would not have been so dramatic and, as a result, the adjustment that countries like Greece, Portugal and Spain undergo since 2009 could have been much less painful. Higher average interest rates for peripheral countries could also prevent macroeconomic imbalances from increasing again in the future. In contrast to the first case, where countercyclical spreads destabilize the economy, here the talk is of equilibrium spreads, constant over time so that they do not interfere with monetary policy. The bottom line of this argument is that the idea of spreads between monetary union countries should possibly not be rejected completely. If financial markets would provide relatively stable spreads of the right size (possibly with some educated guidance of the ECB) the gains for euro area stability could be substantial. Refering again to President Draghi (Draghi, 2013), he also pointed that the ECB would not reduce those parts of sovereign bond yields that are fundamentally justified. This is exactly what our paper is about, although we go one step further and postulate keeping fundamentally justified spreads on private borrowing as well.

While interest rate spreads in a monetary union do not, at first, look like an attractive idea, one has to bear in mind two things. First, if the renewed arrisal of imbalances has to be prevented some sort of break must be put on more spending-oriented parts of the euro area. If these are not spreads (higher price) it must be quantitative restrictions on capital inflows (e.g. limited credit supply). One has to consider what is less appealing in a monetary union. Second, whether one likes it or not, spreads are already there (as well as quantitative restrictions as a matter of fact). With some guidance they could possibly be used to the good.

The idea of using spreads to stabilize a heterogeneous monetary union is, to our knowledge, a new one. The closest thing in the literature in terms of concept and methodology is probably the estimation of equilibrium exchange rates.

To use spreads in the way that we propose, requires knowing the size of their equilibrium levels and this is what this paper provides. We define equilibrium spreads as the difference between a countries real interest rate and the euro area average that would, on average, keep its current account balance in equilibrium. Given the described developments, the 
current account balance seems to provide a relatively universal measure of a currency union member's overheating. To this end we estimate a panel data model and use it to calculate the real interest rate elasticity of the curent account balance. Next, we use the IMF's External Sustainability methodology to calculate equilibrium current account balances for individual euro area member states. Finaly both results are used to calculate theoretical real interest rate spreads that would have bridged the gaps between current account balances and the norms for individual countries.

Our findings show that indeed interest rate spreads could have signifficantly lowered the gaps between current account balances and their equilibrium levels (norms). For the four peripheral countries our estimates of the average gaps in the period 1999-2012 range from -3.4 to -7.8 percentage points. Our baseline estimate of the long-term real interest rate semielasticity of the current account balance is equal to 2.2. It means that an increase of the real interest rate by 1 p.p. leads to improvement of CA balance in the long-term by 2.2 pp. As a result real interest rate spreads against the historical real rate that would have closed the gaps between $\mathrm{CA}$ balances and their respective norms range from 5.8 percentage points in Portugal to 1.5 percentage point in Ireland as far as peripheral countries are concerned.

The rest of the paper is structured as follow. Section two describes the methodology for calculating current account norms (equilibrium levels). Section three presents the data, sections four estimation methods and results. In section five we calculate the theoretical equilibrium spreads. Section six concludes.

\section{Current account norms}

As already mentioned in the Introduction we proceed in three steps. First we calculate reference levels (norms) for current account balances. Second we estimate the real interest rate elasticity of the current account. Finaly, we calculate the interest rates that would have closed the gaps between current accounts and their reference levels. This chapter presents the first step.

The literature on calculating equilibrium/ reference/ norm levels for current account balances is vast. A substantial part of research has been conducted at the International Monetary Fund. Several methodologies were developed by its Coordinating Group on Ex- 
change Rate Issues (CGER) in the 2000s (IMF, 2006; Isard and Faruqee, 2008). So called S-I norms are based on applying medium run values of regressors to coefficients of an estimated CA equation. External Sustainability (ES) norms rely on the notion of stabilizing the net foreig asset to GDP ratio (more details below). A more recent approach of the Fund is the External Balance Assesment (IMF, 2013). This method starts with estimating a current account regression and then applying normative policy benchmark for selected regressors, including the fiscal balance, capital controls and monetary policy. Nevertheless, aside of this fairly advanced method, EBA also uses the ES approach known from CGER.

Apart of the rich methodology of the IMF several academic projects dealt with equilibrium current account positions.

We decided to follow the IMF's External Sustainability (ES) approach embeded in the CGER and EBA methodologies. This method, as described in detail below, is simple and transparent. In particular, ES does not involve discretionary choices. We believe that given our exercise the great simplicity of the norm calculation is a serious advantage. Given how rich the literature on equilibrium $\mathrm{CA}$ balances is we do not want to leave the impression that our results can be made only for ES norms. While clearly the final answer (interest rate spread) depends on the norm, we treat the estimated interest rate semi-elasticities as the main, and fixed ingredient for calculating the spreads. The ES norms only provide an ilustration and if someone has a different view on equilibrium CA balances, it is trivial to substitute it.

The ES methodology calculates the current account balance that stabilizes the net foreign asset position of the economy. It relies on the intertemporal budget constraint which requires that the present value of future trade surpluses suffices to repay the country's external debt. The intertemporal budget constraint can be satisfied by ensuring that the net foreign assets to GDP ratio is stabilized, thus preventing assets or liabilities from growing without bound.

The starting point for calculating the CA norm is the accumulation equation for net foreign assets:

$$
N F A_{t}-N F A_{t-1}=C A_{t}
$$

where $N F A_{t}$ denotes net foreign asset stock and $C A_{t}$ the current account balance. De- 
noting with lower-case letters the ratio of a given variable to GDP this equation can be written as:

$$
n f a_{t}-n f a_{t-1}=c a_{t}-\frac{g_{t}}{1+g_{t}} n f a_{t-1}
$$

where $g_{t}$ stands for nominal GDP growth. Hence, the CA to GDP ratio that stabilizes the net foreign asset position at previous year's level is:

$$
\overline{c a} a_{t}=\frac{g_{t}}{1+g_{t}} n f a_{t-1}
$$

From equation (3) we calculate current account norms for the 11 euro area countries in our sample. Next we calculate the gap between each countries current account position and its norm. Table 6 shows the average current account balance, norm and gap in the sample 1999-2012. Clearly all numbers differ between countries. In particular the peripheral countries that noticed large current account deficits also show the biggest gaps between CA balances and norms, ranging from ... in Ireland to 8.5\% of GDP in Greece.

\section{Data}

The analysis has been conducted for 11euro area countries which formed primarily the monetary union: Austria, Belgium, Finland, France, Germany, Greece, Ireland, Italy, Netherlands, Portugal and Spain. Due to high share of the financial sector to GDP, which may distort the estimation results we excluded Luxemburg from the sample. The time span used for estimation covers the period from 1995 to 2012 what provides for 18 annual observation. Despite of the fact that monetary union has been established in 1999 we used data since 1995. In the period preceding euro adoption the fluctuations of the nominal exchange rates for that countries have been rather limited and that is why due to short time series and relative small number of countries in the sample we decided to lenghten our sample by 4 years what should make the estimation results more robust.

The choice of the proper single interest rate, which determines the relationship between domestic savings and investments and finally country's CA position is not straightforward. The heterogeneity in the structure of the savings across the euro area countries, the changes 
in its structure over time as well as different horizon for savings and investments motivate us to use several measures of interest rates. In fact we employed three different interest rates: the yield on ten years sovereign bonds, the lending rate expressing the average lending rate for non-financial sector and the deposit rate, which reflects the average interest rate on deposits from non-financial sector. The yield on sovereign bonds is a long-term interest rate while two latter variables may be perceived as medium-term interest rates.

While investigating the role of the interest rates in determining the current account balance we should also account for other variables which influence the relationship between domestic investments and savings in the medium- to long term and are not related to the business cycle. The list of potential determinants of the CA balance is very comprehensive (see IMF (2013)) and depends on both the underlying theory and the sample of the countries under interest. While selecting the abovementioned control variables we focus only on the "structural" indicators to avoid in the model the contemporaneous relationship with the interest rates. The idea behind this approach is to allow the interest rate capturing the whole cyclical component of the CA movement. Among the most widely used structural determinants of the $\mathrm{CA}$ which are also suitable for the euro area countries we can list the following variables: net foreign assets position, demographic factors, structural fiscal balance, the variables expressing the stage of development like GDP per capita or productivity, rule of law and capital to output ratio. Furthermore we describe the selected control variables and its expected impact on the CA balance.

- Net foreign assets (NFA) position. In the literature the most specifications of the CA equation include the country's lagged (initial) NFA position expressed usually in relation to GDP. However the sign of the relationship with the CA balance is ambiguous. From the one side the countries with more positive NFA position tend to have higher CA balance not only via trade balance, which usually is the primary cause of the positive NFA stock but also due to more favorable income balance stemming from higher net foreign investments. On the other hand the countries with less favorable NFA position may afford for lower trade balance to maintain the constant NFA relationship to GDP what leads to negative correlation with the CA balance. The potentially negative relationship between initial NFA position and CA may also result from the fact 
that highly indebted countries may be forced to improve their current account balance to increase their solvency. The latter explanation may be suitable for the euro area countries in the period covered by our research. In the regression we use the lagged value of NFA stock to avoid the reverse relationship with the CA.

- The demographic factors - we expect the negative association between the number of economically dependents in the population and the level of national savings and furthermore CA balance. Following literature we account for the demographic factors in the model by using a variable expressing population growth.

- The stage of development - in the convergence process the lower income countries due to shortage of domestic savings are usually forced to finance investments by external borrowing what results in the CA deficit. This process stays in line with the theory that the capital flows from the higher to lower productivity countries. We express the stage of development by two alternative measures: GDP per capita and the level of productivity, testing for their significance.

- Structural fiscal balance - according to several theoretical models (like overlapping generations models) we may expect the positive relationship between fiscal deficit/surplus and $\mathrm{C} / \mathrm{A}$ balance. However in case when Ricardian equivalence holds the changes in the budget deficit are perceived by the households and firms as temporary and reversible and do not shift the relationship between savings and investments/consumption. Then the impact on the $\mathrm{CA}$ will be insignificant. In the model we test the significance of the fiscal balance in respect to CA. To avoid the contemporaneous link with the interest rates we use the structural fiscal balance (in relation to GDP) i.e. fiscal balance adjusted for the business cycle .

- Rule of law - better institutions and regulations increase productivity and export performance in many ways. Firstly, they reduce quasi-fixed costs like corruption or time needed to complete administration duties. Secondly, they minimize unnecessary uncertainty in business doing, resulting from e.g. low contract enforcement, which allows firms to plan long-term investments or cooperate and make use of synergy. As a variable in the model we use perceived rule of law from World Governance Index dataset. 
We expect the parameter's sign to be positive.

- Capital to output ratio - this variable represents endownment in capital and is a proxy for foreign capital needs. Moreover, more productive techonologies are usually capitalemboddied, therefore we expect the sign to be positive.

The data we use come from IMF, Eurostat and AMECO database.

\section{Estimation results}

\subsection{Estimation methods}

In panel data analysis of macroeconomic data, the dynamic nature of a process is often ignored by researchers, partly due to econometric limitations (see below). Indeed, a number of panel data studies on CA use static models with autocorrelation correction IMF (2013). In this paper, we decide to include a lagged $\mathrm{CA}$ on the right hand side in the regression. Our arguments for such an approach are as follows. Firstly, one of our goals is assess the long-term effect of real interest rate changes on CA. Thus, while in static specification we assume that all shocks in explanatory variables materialize in CA only in the same period, in the dynamic case the long-term impact of change in explanatory variable $x_{k}$ is given by $\frac{x_{k}}{1-\rho}$, where $\rho$ stands for autoregressive coefficient at lagged dependent variable. Secondly, if a lagged dependent variable should be included in our specification, is also conditional on our view on the state-dependency of CA. In our view agents' decision on whether to invest abroad or trade with foreign markets is affected by the past choices. Factors like (partial) irreversibility of investment, sunk costs of foreign market research, long-term contractual agreements between parties or involvement into global supply chains may be a good example in here. Thirdly our approach allows us to adress the issue of autocorrelation existing in the data as well.

On the other hand, we are not in favour to use panel ECM models proposed by Pesaran and Smith, 1995; Pesaran et al., 1997. Instead, we prefer to include lagged dependent variable to control for autocorrelation and year dummies to control for common shocks and possible trends in the data. Firstly, time dimension of 18 observations may seem quite large for a 
panel dataset, it is rather small for cointegration time-series methods. Secondly, power of unit root test for our dataset seems rather low, as their asymptotic properties depend on $T$ and $N$ being large.

As well documented in the literature, OLS yields inconsistent estimates in presence of unobserved heterogeneity. In the dynamic specification, a bias of OLS autoregression coefficient is positive (Baltagi, 2005). A straightforward way to deal with heterogeneity between units and omitted variable bias would be to include a set of country dummies, i.e. fixed effects. However, it is often the straightforward way to make parameter estimates of rather timeinvariant variables insignificant, even if their importance for a given economic phenomenon is deeply verified and documented in the theoretical literature Plümper et al. (2005). Fortunately, interest rates that we focus on show enough volatility over time. The second (and far more important) problem with fixed effects approach is, however, a downward bias of autoregressive coefficient, known as Nickell bias after the seminal Nickell (1981) work. This bias is especially important in short datasets with highly persistent variables, as it diminishes as $T \rightarrow \infty$ but is significant if $\rho \rightarrow 1$. In our case, $T=18$ which may diminish bias, yet the dependent variable is highly persistent (autocorrelation coefficient of first order is as big as 0.95 and autocorrelation coefficient of even third order is still higher than 0.8).

One way to deal with Nickell bias it is to use instrumental variable estimation, such as Anderson and Hsiao (1982) first-difference estimator (FD). However, apart from the fact that asymptotic efficiency of FD estimator is dependent from sample's cross-section dimension (which is very low in our case), weak instrumentation issues can make FD estimation a cure worse than disease. This is also the case for us. For all three interest rates the F-statistic in first-stage regression is far below 10 (which is a rule-of-thumb value to identify problems with weak instrumentation, following influential work byStaiger and Stock, 1997) and KleibergenPaap Wald rk F statistic is unacceptably low (less than 2, while 19.93 critical value by Stock and Yogo (2002) corresponds to 10\% IV bias). Similarly, high autocorrelation of dependent variable weakens instruments also for Difference-GMM estimator (seeBlundell and Bond, 1998). As a cross-check, we also used System-GMM estimates that have better properties if $\rho \rightarrow 1$, keeping in mind that due to overidentification (large number of instruments relative to the number of observations) they should be interpreted with great caution (see Roodman, 
2009 for extensive discussion). These results, however, are similar to those obtained by OLS and FE estimators and are available on request.

An additional way to test the strength of Nickell bias in our case is to use bias-corrected dynamic fixed effects estimator. These borrow from Kiviet (1995) and later works by Judson and Owen, 1997; Bun and Kiviet, 2003, 2006). A number of Monte Carlo studies show that Nickell bias may be sizeable even if $T$ is large, such as $T=18$, especially if autocorrelation coefficient is high. Therefore we employ a bias-corrected estimator as a benchmark .

As noted in Mátyás and Sevestre (2008), fixed effects and OLS estimates may serve

as lower and upper bounds for our results. Given the above-listed pros and cons of each estimator, in the context of relatively long time dimension of a dataset it is reasonable to assess the possible magnitude of Nickell bias by comparing it with OLS and bias-corrected fixed effect model. For the reasons listed above, we do not use GMM methods that could be fine in some macroeconomic applications but for different dataset size, e.g. ones with all countries in the world and shorter time dimension.

\subsection{Estimation results}

Now we turn to the estimation results for AR(1) model (with year dummies), namely OLS, FE and bias-corrected FE. Table 3 shows estimation results for our basic specification with three real interest rates. As expected, OLS estimates of parameter $\rho$ are somehow larger than those of FE. However, reported estimates using Bruno, 2005 estimator are almost the same as FE estimates which suggest that Nickell bias seems negligible in our context, and, consequently, that it is OLS estimates that suffer from (omitted variable) bias. Signs of OLS results seem, though, to be well in line with the expectations. Parameter for real interest rate is always postive and significant in OLS model, regardless of the choice of interest rate. Shrinking (ageing) society is more likely to be dissaving and therefore soaking up the capital from abroad. Although population change did not always turn statistically significant in FE specification (partly because of its low volatility in time), due to strong priors we keep this variable in the FE model. Finally, negative sing of lagged NFA coefficient shows that no country may run CA deficits/surpluses forever. When turning from OLS to FE, estimates of lagged GDP per capita level lose their significance (and even changes their sign, which is 
irrelevant as they are statistically equal to zero). However, this is what could be expected, given the relatively low volatility in time of GDP level (as percentage of EU average). We drop this variable from FE model. On the other hand, parameters for real interest rate and lagged net foreign assets to GDP remain strongly significant also in FE model. From our list of potential CA determinants listed in section 3 the remaining varaiables: structural deficit, rule of low and capital to output ratio are statistically insignificant in all considered models, do not influence our core results, and we exclude them from the final model.

Arellano-Bond test for autocorrelation shows that including lagged dependent variable reduces problems with autocorrelation. At no reasonable significance level the null hypothesis (i.e. that there is no autocorrelation) should be rejected. For the sake of heterogeneity we use robust standard errors.

It is note to worth that, not surprisingly, the estimates for the real interest rate parameter are visibly higher (and more significant) for the long-term interest rate (Maastricht rate) than for deposit rate or lending rate. Significance of country dummies (both in a static and dynamic specification), as well as difference between OLS and FE estimates suggest that it is the latter that should be our preferable choice. It should be also noted that dynamic fixed effect estimates, though biased, have relatively small variance, especially if compared to consistent estimators as GMM(Mátyás and Sevestre, 2008) or bias-corrected FE.

\section{$5 \quad$ Equilibrium spreads}

In the next step we are going to assess to what extent a potentially stronger than historically observed divergence in the level of real interest rates between euro area countries could have prevented these economies against so substantial increase of external imbalances in the period after forming the monetary union and fixing the nominal exchange rates. To answer this question we conducted a counter-factual simulation, in which for every country individually we set the hypothetical level of the real interest rates which would stabilize their CA balance. As discussed in section 2 a definition of stable or equilibrium current account balance is not

ambiguous. In the simulation we use a concept of the equilibrium CA based on the country's external sustainability as proposed by the IMF and described in section 2 . Therefore as a stable CA balance we define the value of the current account which stabilizes the stock of 
net foreign assets at the level from the preceding period. We base our simulation on the estimation results for the panel data presented in section 4 . The model we use is a dynamic panel model with a lagged dependent variable on the right hand side. That is why we can differentiate between short-term (or immediate) influence of the real interest rate on the CA balance and its long-term impact which differ substantially to the previous one. The coefficient at the real interest rate in the model is relatively low what means that an attempt to stabilize CA in every period by changing interest rates simultaneously is very costly and demands high volatility of real interest rates. The low value of this coefficient may result from the fact that the transmission mechanism of the interest rates on the relationship between savings and investments/consumption takes longer than one year only. We addressed this problem by allowing for the dynamics in the model. As a result we get the value of the long-term multiplier which is in average 6 times larger than short-term multiplier. Taking this into account the appropriate strategy to avoid excessive interest rates volatility would be to stabilize the average value of the $\mathrm{CA}$ balance in the certain period longer than one year instead of stabilizing CA balance in every year. Moreover regarding the discrepancy between short- and long-term multiplier it would be more efficient to set the interest rates at the desired level with some lead in respect to the reference period. However when we are going to stabilize the average value of the current account in the certain period it can be an infinite number of interest rate paths which fulfil this criterion. In the simulation we decided to choose a simple and rather intuitive solution: we increase the interest rate in the first year to the desired level and keep the spread to the actual interest rate constant over time. This approach allows us to keep some factual volatility of interest rates, which has been invoked by other than CA factors as well.

In our exercise two significant drawbacks should be mentioned. Firstly we have to take into account the recursive spillover between NFA and desired CA balance, which occurs in the simulation in two ways. The first spillover results from the fact that one of the explanatory variables in the model is a lagged NFA position, which by definition is directly related to the value of CA balance (the NFA stock in the certain period equals approximately the NFA stock from the preceding period plus CA balance). In the counter-factual simulation when the value of $\mathrm{CA}$ balance is being changed as a result of different counter-factual interest rates 
path we should also accommodate this change in the NFA position. Then via negative sign of the respective coefficient in the model described in section 4 an increase in the NFA stock lowers further the CA balance in the next period. The second spillover occurs via the norm for the current account, which depends on the NFA stock from the preceding period. With the assumption of positive nominal GDP growth a stronger NFA position allows a country to afford for weaker CA to keep NFA to GDP constant. That is why the new counter-factual values of NFA stock have two recursive effects on the desired counter-factual CA value. While we target to set interest rate to close the gap between actual $\mathrm{CA}$ and its norm these two effects act in the opposite directions. However as the coefficient at lagged NFA in the model is higher than one in modulus (for deposit and lending rate) the first effect may be slightly stronger.

Secondly it is very likely that real interest rate may have an impact on the nominal GDP which is used in the calculation of the norm for the CA. However becouse the model is a single-equation panel model we cannot justify this effect. To summarize in the simulation we explicitly take into account the recursive relationship between CA and the lagged NFA position but disregard the potentially weaker and more difficult to quantify relationship between interest rates and nominal GDP used for calculation of the norm.

Accordingly our exercise has been designed as follows. The estimation sample covers the period from 1995 to 2012 what results is 18 annual observation. Thus for each country we are going to find a level of real interest rates, which would stabilize the average CA in the period from adopting euro in 1999 (in 2001 for Greece) to the onset of the global financial crisis in 2007. It means that a difference between CA and the norm for the CA derived as proposed in Section 2 for years 1999-2007 must be zero in average (2001-2007 for Greece). However taking into account the substantial discrepancy between values of short- and long-term multipliers we set the interest rates at the desired level already two years before adopting euro (in 1999 for Greece and in 1997 for remaining ten countries). This assumption stays in line with the observation that approximately 1,5-2 years before euro adoption the financial markets started to perceive the certain country as a euro area member state what resulted in acceleration of nominal interest rates convergence and a substantial decrease of spread against euro area average interest rate. 
We collected the outcome of the simulation in Table 2. In the subsequent columns we presented the results for three different interest rates: the yield on 10 years sovereign bonds, the lending rate and the deposit rate all of them adjusted for inflation. The numbers in the table are the differences between actual real interest rates and a respective desired real interest rates, which close the average gap between actual CA and its norm in years 1999-2007 (2001-2007 for Greece). The results clearly show that for four euro area countries: Ireland, Portugal, Greece and Spain the historical real interest rates were too low to preserve these economies against building up of external imbalances. The highest discrepancy between actual and desired interest rates has been observed for Portugal and Greece. Depending on the choice of the interest rate a difference ranges from 0,058 to 0,075 for Portugal and from 0,043 to 0,054 for Greece. Slightly lower but still negative spread between historical and desired rates has been achieved for Spain $(0,02-0,025)$ and Ireland $(0,015-0,02)$. For two countries: France and Italy the historical real interest rates were almost in line with the simulated counter-factual rates. Five euro area countries experienced real rates, which resulted in the average surpluses of current accounts over its norm in the reference period what lead to an increase of NFA position over the sample. For these countries the historical real rates were above the desired rates by 0,013 to 0,016 in case of Belgium, by 0,017 to 0,022 for Austria and by 0,019 to 0,025 for Germany. The highest positive discrepancy between historical rates and the rates stabilizing CA balance have been achieved for Netherland $(0,047-0,06)$ and Finland $(0,077-0,101)$. Thus the results for Finland may be to some extent biased by large jumps in the NFA stock in years 1999-2000 due to valuation effect. If we exclude these two years from the sample the spread for Finland decreases to the level obtained for Netherlands (but still remains large). At this stage it is worth to remind that according to the definition adopted in our paper the desired level of real interest rate is the level which ensure the stability of net foreign assets position, which in general doesn't guarantee a zero current account balance. The attempts to get the zero current account balance by adjustment in interest rates only would have result for some economies in significantly higher spreads than presented in Table 2. We are aware that in some cases the reasons for substantial increase of current account deficits were to some extent not related to the level of interest rates balancing domestic savings and investments/consumption but resulted from structural 
weaknesses of the export what has been pointed out by Gaulier and Vicard (2012). On the other hand for some countries a permanent surpluses in trade balance were due to exportoriented model of growth.

In Table 2 we collected the results of the simulation in terms of spreads to the historical real interest rates. However despite of the fact that up to 2007 the differences in historical nominal interest rates between euro area member states were in general negligible the real interest rates differed due to discrepancy in the inflation rates (and inflation expectations). That is by presenting the counter-factual average historical real interest rates calculated as a sum of spreads from Table 2 and the historical average real rates for years 1999-2007 we may obtain more clear picture of divergence between real interest rates necessary to protect euro area countries against building up external imbalances. We presented the counter-factual average interest rates on Figure 1 for long-term (10y sovereign bonds yield) interest rates. For comparative purpose we expressed the rates in terms of spread against Italy because for this country the actual interest rates were in line with the norm ensuring stability of NFA position. The results presented on Figure 1 allow classifying the euro area countries into some groups in respect to the level of real interest rate adequate to stabilize CA balance in period 1999-2007. For three euro area countries: Italy, France and Ireland the desired real long-term interest rate would be the same and equal in average to the level observed historically for Italy. Three other countries (Germany, Austria and Belgium) should have had lower real interest rate than Italy by 1,0-1,5 pp if they had targeted CA balance close to its norm. For Netherlands and Finland the desired real interest rates stabilizing CA would have had been significantly lower: by almost $5 \mathrm{pp}$ for Netherland and even more for Finland but for the latter we should keep in mind that the results may be impaired by the sudden jumps in NFA position mentioned above. On the other hand Spain should have had real interest rates higher by ca. 1 pp than Italy, France and Ireland while for Greece this spread should have equaled to $3 \mathrm{pp}$. According to the expectations the highest spread would have been derived for Portugal amounting to $5 \mathrm{pp}$. in respect to Italy. 


\section{Conclusions}

This research project originates from two observations. First, large macroeconomic imbalances plagued the euro area since its creation. Peripheral countries faced too low interest rates which increased domestic demand, undermined competitiveness and resulted in large curent account deficits. Second, substantial interest rate spreads emerged recently between member countries of the euro area. In fact, these spreads played an important role in destabilizing the euro area, since spreads increased most in countries in deepest recession.

In this paper we check whether interest rate spreads could potentially play a stabilizing role as well. Instead of time varying spreads, we consider constant spreads, higher for countries with a higher propensity to spend, lower in more saving-oriented coutries. To this end we estimate a model that links current account deficits to real interest rates, and then calculate by how much real interest rates would have to differ in order to bring current account balances to assumed targets. Our results show that spreads between real interest rates of 1.5 to 5.8 percentage points would be necessary to reduce current account deficits in the four peripheral countries (Greece, Portugal, Ireland and Spain) to levels that would have stabilized these countries net foreign asset positions.

The policy conclusion from this paper is that instead of fighting spreads accross the board, the ECB could accept their existence, provided that they behave in a relatively stable way and are close to the equilibrium levels that we calculate. Otherwise it cannot be excluded that the history of diverging current account balances, lost competitiveness and sharply rising spreads at the least desireable moment will repeat itself in a few years. 


\section{References}

Anderson, T. W., and Cheng Hsiao (1982) 'Formulation and estimation of dynamic models using panel data.' Journal of Econometrics 18(1), 47-82

Baltagi, Bagi H. (2005) Econometric Analysis of Panel Data. Third Edition, 3. ed. ed. (Wiley)

Blanchard, Olivier (2007) 'Adjustment within the euro. The difficult case of Portugal.' Portuguese Economic Journal 6(1), 1-21

Blundell, Richard, and Stephen Bond (1998) 'Initial conditions and moment restrictions in dynamic panel data models.' Journal of Econometrics 87(1), 115-143

Brixiova, Zuzana, Laura Vartia, and Andreas Worgotter (2009) 'Capital inflows, household debt and the boom-bust cycle in Estonia.' OECD Economics Department Working Papers 700, OECD, Economics Department

Bruno, Giovanni S. F. (2005) 'Estimation and inference in dynamic unbalanced panel-data models with a small number of individuals.' Stata Journal 5(4), 473-500

Brzoza-Brzezina, Michał, Pascal Jacquinot, and Marcin Kolasa (2014) 'Can we prevent boom-bust cycles during euro area accession?' Open Economies Review. fortcoming

Bun, Maurice J. G., and Jan F. Kiviet (2003) 'On the diminishing returns of higher-order terms in asymptotic expansions of bias.' Economics Letters 79(2), 145-152

Bun, Maurice J.G., and Jan F. Kiviet (2006) 'The effects of dynamic feedbacks on ls and mm estimator accuracy in panel data models.' Journal of Econometrics 132(2), 409-444

Draghi, Mario (2012) 'Rationale and principles for financial union.' Speech by Mario Draghi, President of the ECB at the 22nd Frankfurt European Banking Congress, Frankfurt, 23 November 2012

_ (2013) 'Strengthening financial resilience.' Speech by Mario Draghi, President of the ECB, at the 2013 International Monetary Conference, Shanghai, 3 June 2013

ECB (2003) 'Inflation differentials in the euro area: potential causes and policy implications.' ECB Report, European Central Bank

Gaulier, G., and V. Vicard (2012) 'Current account imbalances in the euro area: competitiveness or demand shock?' Quarterly selection of articles - Bulletin de la Banque de France (27), 5-26 
Honohan, Patrick, and Anthony J. Leddin (2006) 'Ireland in EMU - more shocks, less insulation?' The Economic and Social Review 37(2), 263-294

IMF (2006) 'Methodology for cger exchange rate assessments.' Background paper, International Monetary Fund

_ (2013) 'External balance assessment (EBA) methodology: tehcnical background.' Background paper, International Monetary Fund

Isard, Peter, and Hamid Faruqee (2008) 'Exchange rate assessment: Extension of the macroeconomic balance approach.' Occasional Paper 167, International Monetary Fund

Judson, Ruth A., and Ann L. Owen (1997) 'Estimating dynamic panel data models: a practical guide for macroeconomists.' Finance and Economics Discussion Series 1997-3, Board of Governors of the Federal Reserve System (U.S.)

Kiviet, J. F. (1995) 'On bias, inconsistency, and efficiency of various estimators in dynamic panel data models.' Journal of Econometrics

Kuodis, Raimondas, and Tomas Ramanauskas (2009) 'From boom to bust: Lessons from Lithuania.' Monetary Studies 1, Lietuvos Bankas

Mátyás, L., and P. Sevestre (2008) The Econometrics of Panel Data: Fundamentals and Recent Developments in Theory and Practice Advanced Studies in Theoretical and Applied Econometrics (Springer)

Nickell, Stephen J (1981) 'Biases in dynamic models with fixed effects.' Econometrica $49(6), 1417-26$

Pesaran, M. H., Y. Shin, and R. P. Smith (1997) 'Pooled estimation of long-run relationships in dynamic heterogeneous panels.' Cambridge Working Papers in Economics 9721, Faculty of Economics, University of Cambridge, August

Pesaran, M. Hashem, and Ron Smith (1995) 'Estimating long-run relationships from dynamic heterogeneous panels.' Journal of Econometrics 68(1), 79-113

Plümper, Thomas, Vera E. Troeger, and Philip Manow (2005) 'Panel data analysis in comparative politics: Linking method to theory.' European Journal of Political Research 44, 327354

Roodman, David (2009) 'A note on the theme of too many instruments.' Oxford Bulletin of Economics and Statistics 71(1), 135-158 
Staiger, Douglas, and James H. Stock (1997) 'Instrumental variables regression with weak instruments.' Econometrica 65(3), 557-586

Stock, James H., and Motohiro Yogo (2002) 'Testing for weak instruments in linear iv regression.' NBER Technical Working Papers 0284, National Bureau of Economic Research

Zdarek, Vaclav, and Juan Ignacio Aldasoro (2009) 'Inflation differentials in the euro area and their determinants - an empirical view.' Kiel Advanced Studies Working Papers 450, Kiel Institute for the World Economy 


\section{Tables and figures}

Table 1: Current accounts, norms and gaps

\begin{tabular}{cccc}
\hline Country & CA balance & CA norm & CA gap \\
\hline Austria & 1.9 & -0.6 & 2.4 \\
Belgium & 1.9 & 1.5 & 0.4 \\
Finland & 4.0 & -2.1 & 6.1 \\
France & -0.2 & -0.1 & -0.1 \\
Germany & 4.0 & 0.4 & 3.6 \\
Greece & -8.6 & -1.6 & -7.0 \\
Ireland & -1.1 & 0.7 & -1.9 \\
Italy & -1.1 & -0.3 & -0.8 \\
Netherlands & 6.0 & -0.2 & 6.1 \\
Portugal & -9.0 & -1.2 & -7.8 \\
Spain & -5.2 & -1.8 & -3.4 \\
\hline
\end{tabular}

Note: The table presents average valueas for the period 1999-2012, all numbers expressed in per cent of GDP.

Source: Own calculations.

Table 2: Spreads between actual and desired real interest rates (stabilizing NFA stock).

\begin{tabular}{c|ccc}
\hline Country & Maastricht rate & Depo rate & Lending rate \\
\hline Finland & $-0,077$ & $-0,087$ & $-0,101$ \\
Netherlands & $-0,047$ & $-0,052$ & $-0,060$ \\
Germany & $-0,019$ & $-0,022$ & $-0,025$ \\
Austria & $-0,017$ & $-0,020$ & $-0,022$ \\
Belgium & $-0,013$ & $-0,015$ & $-0,016$ \\
France & $-0,005$ & $-0,007$ & $-0,007$ \\
Italy & 0,000 & 0,000 & 0,000 \\
Ireland & 0,015 & 0,018 & 0,020 \\
Spain & 0,020 & 0,022 & 0,025 \\
Greece & 0,043 & 0,047 & 0,054 \\
Portugal & 0,058 & 0,065 & 0,075
\end{tabular}

Source: Own calculations. 


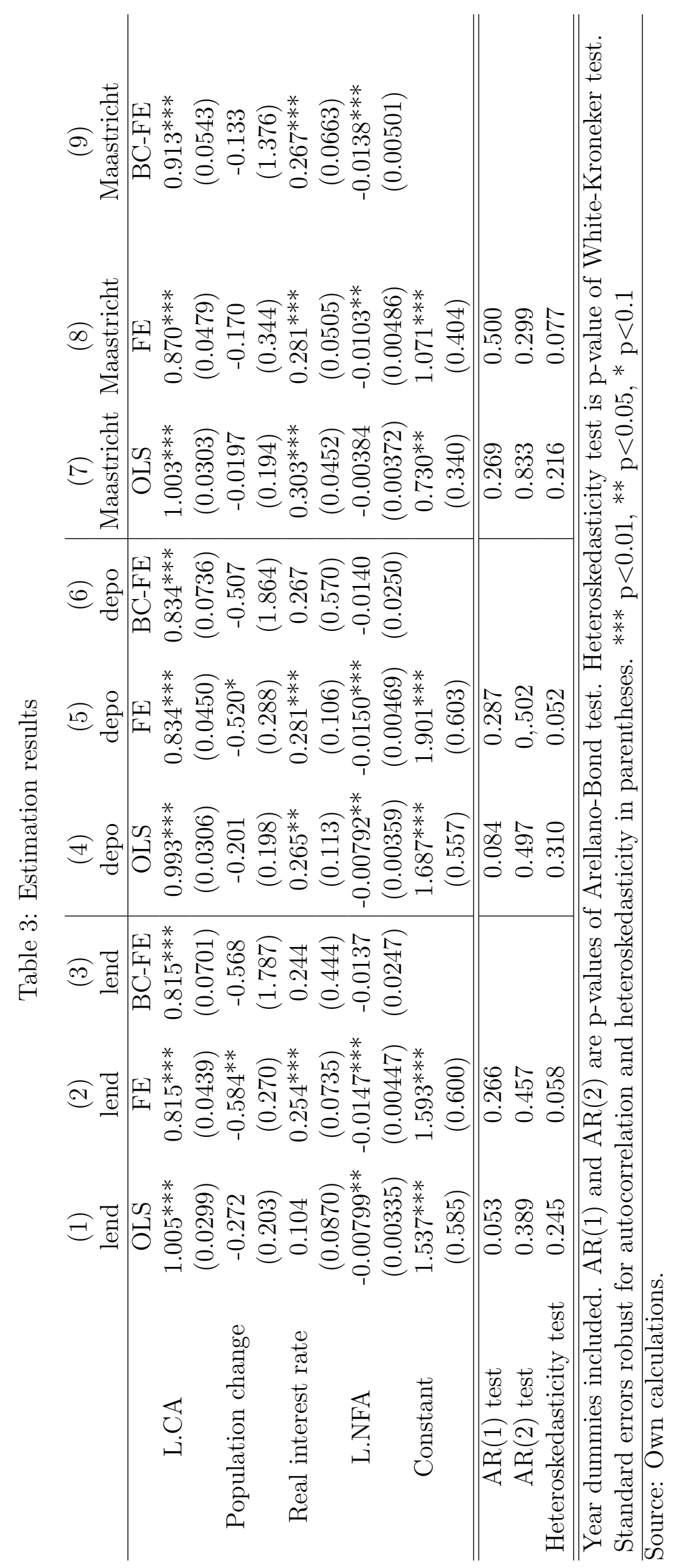


Figure 1: Spreads of counter-factual real interest rates vs Italy.

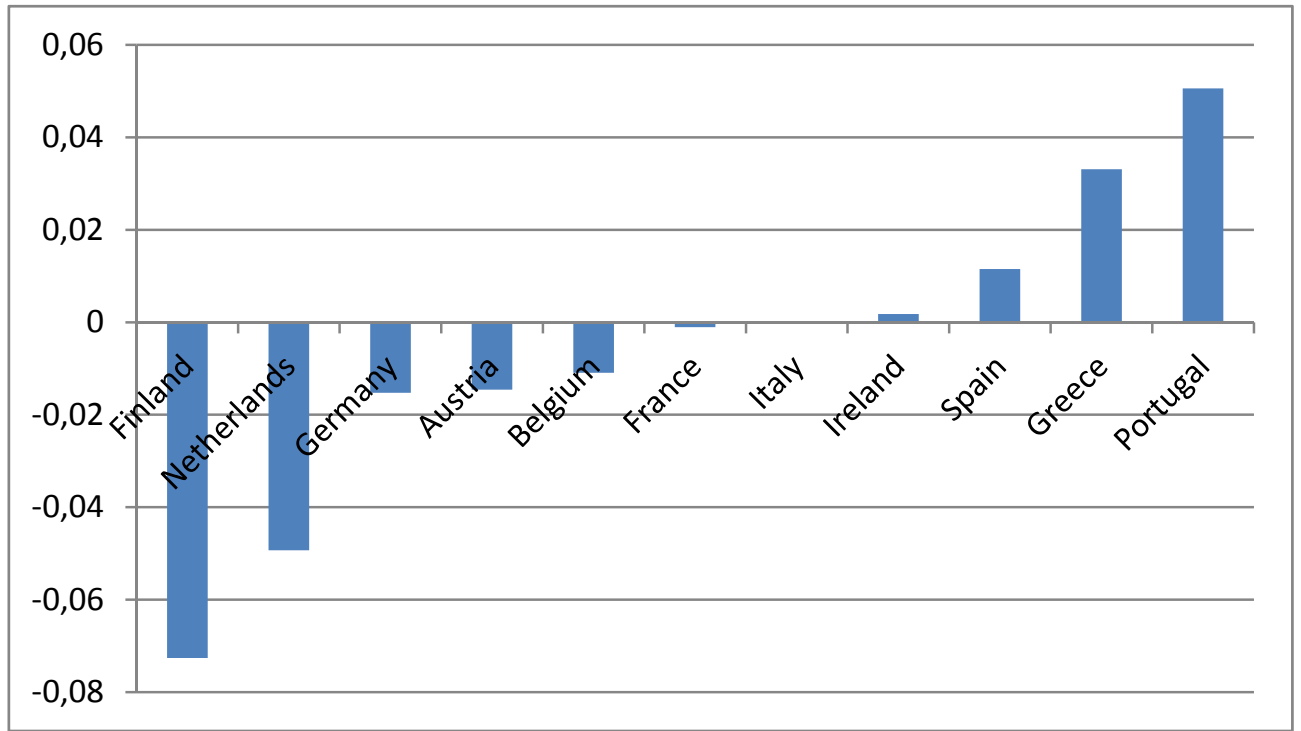

